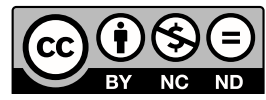

Estudos Teológicos foi licenciado com uma Licença Creative Commons Atribuição - NãoComercial - SemDerivados 3.0 Não Adaptada

http://dx.doi.org/10.22351/etv59i2.3765

\title{
EXÉGESIS, TEXTO E IMAGINARIO ${ }^{1}$
}

\author{
Exegesis, text and imaginary
}

\section{César Carbullanca Núñez ${ }^{2}$}

Resumen: En el contexto del pluralismo de métodos exegéticos y de un riesgo de una promiscuidad teórica y metodológica, el artículo esboza los desafíos actuales de una teoría semiótica general de la palabra de Dios tomando como punto de partida la crítica de los métodos histórico crítico como ideología, lo cual conlleva el desafío de situar los textos en relación al concepto regional de texto. La alternativa del empleo de métodos diacrónico/ sincrónico no es meramente instrumental e implica responder a cuestiones fundamentales de una semiótica general. La profundización de los conceptos regionales del texto en los actuales estudios exegéticos conlleva comprender la abstracción ideológica que implica extraer los textos de la cultura y el esfuerzo por respetar la ideología del texto. De acuerdo a lo dicho y en vista de nuestro objetivo emplearemos un concepto semiótico de ideología formulado por T. van Dijk y L. Althusser el cual establece una relación entre el concepto de ideología y el de discurso, para luego, discutir las diversas comprensiones del texto en la actualidad.

Palabras claves: Ideología. Mito. Imaginario. Lenguaje.

Abstract: In the context of the pluralism of exegetical methods and of a risk of a theoretical and methodological promiscuity, the article outlines the current challenges of a general semiotic theory of the word of God taking as a starting point the critique of critical historical methods as ideology, which entails the challenges of placing the texts in relation to the regional concept of text. The alternative of the use of diachronic / synchronous methods is not merely instrumental and implies answering fundamental questions of a general semiotics. The deepening of the regional concepts of the text in current exegetical studies entails understanding the ideological abstraction that involves extracting the texts of culture and the effort to respect the ideology of the text. According to what has been said and in view of our objective we will use a semiotic concept of ideology formulated by T. van Dijk and L. Althusser which establishes a relationship between the concept of ideology and that of discourse, and then discuss the various understandings of the text today.

Keywords: Ideology. Myth. Imaginary. Language.

1 O artigo foi recebido em 31 de junho de 2019 e aprovado em 12 de novembro de 2019 com base nas avaliações dos pareceristas ad hoc.

2 Doutor. Pontificia Universidad Católica de Chile, Santiago, Chile. Centro de estudios de la religión UC. E-mail: ccarbull@uc.cl 


\section{Introducción}

\section{El problema}

En el trabajo exegético profesional, los estudios de postgrado se realizan en una cultura, en un lugar y en un tiempo específico. En nuestra labor intelectual vamos con nosotros mismos, con nuestra propia cultura, con nuestras inquietudes, nuestros intereses y preguntas, con nuestra biografía y formación, con nuestros sesgos inconscientes a cuestas. Pero además, en la actual investigación bíblica el grupo de Jesus seminary comprende que la búsqueda de una nueva síntesis atraviesa, entre otras cosas, en alcanzar un nuevo concepto de texto el cual incluya la comprensión del texto en el seno de modelos culturales, asi autores como Ch. Horsley ${ }^{3}$ Carl Holladay ${ }^{4}$, J. Dewey se hacen parte de la crítica. Este último comienza su texto señalando que "los últimos ciento cincuenta años el evangelio de Marcos ha sido el más requerido para la reconstrucción del Jesús histórico" y más adelante señala apropiándose las palabras de David Parker "el concepto de evangelio que está fijado en forma, autoritativa, y final como una pieza de literatura tiene que ser abandonado". Horsley señala que el texto bíblico fue en su origen oral, multi-forme e inestable. El concepto de "texto estándar" como lo ha levantado la exegesis nord-atlántica se aleja de la experiencia textual de las primeras comunidad y exige un replanteamiento. No sin razón, diversas voces han apuntado a la cuestión sobre el carácter ideológico que posee el concepto de texto empleado por la exégesis de los métodos histórico crítico, así p.e. H. Assmann escribía en los años 70:

Los exégetas siguen, bastante tranquilamente, en la elaboración de 'hermenéuticas bíblicas'. Revelan, por otra parte, una frecuente insensibilidad, tanto para los datos de las ciencias humanas, como para las urgencias de la praxis. La estrecha interdependencia entre su postura política ingenua, a veces claramente reaccionaria y sus "principios hermenéuticos" (así como su noción de "revelación”) es un capítulo de la historia de la ideología que está por escribirse ${ }^{6}$.

Ciertamente en contra y de manera paradojal a la pretensión científica que propugnaba el método, la cuestión de los prejuicios con los cuales abordaba el trabajo con los textos llevó a diversos estudiosos a la impugnación ideológica según lo expresaba K. Lehmann con una terminología post-conciliar "para nosotros hoy ha llegado a ser

3 Cf. HORSLEY, Richard. Jesus-in-context: A relational Approach. p. 207-239. Especialmente p. 237. In: HOLEMN, Tom; PORTER, Stanley (Ed.). Handbook for the Study of the Historical Jesus. Leiden; Boston: Brill, 2001.

4 Cf. HOLLADAY, Carl. New Testament Christology: some considerations of method. Novum Testamentum, v. XXV, n. 3, p. 257-278, 1983.

5 Cf. DEWEY, John. The historical Jesus in the gospel of Mark. p. 1.821-1.853. Especialmente 1.836-1.837. In: HOLEMN; PORTER, 2001.

6 ASMANN, Hugo. Teología desde la praxis de la liberación. Ensayo teológico desde la América dependiente. Salamanca: Sígueme, 1973. p. 101. 
evidente y natural la impregnación ideológica que presentan no pocas etapas del método histórico crítico"7 y H. Assmann criticaba también a la exégesis: "[...] yo honestamente no creo que se pueda, sin una gran purificación ideológica, partir de la Palabra porque ella no está disponible, no está libre y es cautiva"». La cita de Assmann merece una explicación. Dicha cautividad consiste en un sometimiento ideológico del texto sagrado por una racionalidad científica la cual presupone un determinado concepto de texto positivista, entendido como fuente de información histórica. La discusión por el carácter ideológico de la exégesis se produce en medio de una crisis epistemológica ${ }^{9}$ y lingüística ${ }^{10}$ que acontece a los estudios bíblicos.

\section{La cuestión ideológica}

El carácter ideológico del concepto de texto empleado por los métodos histórico críticos es antigua y se basa en las propias pre-comprensiones, presupuestos epistemológicos no confesados empleados por los exégetas en su labor y que están a la base de estos métodos y de -cualquier método-. En su momento la relación ideología/ ciencia el mismo cardenal J. Ratzinger, señalaba:

[...] la palabra interpretación nos da una clave para la cuestión en sí: toda exégesis exige un "inter", un entrar y estar "entre" dos o entre las cosas; este es el espacio del propio interprete: la objetividad pura es una abstracción absurda ${ }^{11}$.

\section{Y luego en opinión de Armando Levoratti}

[...] Bultmann se preguntaba si es posible una exégesis sin presupuestos. Su respuesta, como es bien sabido, fue decididamente negativa, y hoy todos los que se ocupan de hermenéutica le dan la razón. Llevamos demasiado de nosotros mismos -nuestra cultura, nuestras inquietudes personales y nuestras tradiciones-para que sea posible una exégesis totalmente desencarnada ${ }^{12}$.

No son pocos los que han acusado a la propia racionalidad ilustrada de constituirse en el mito de la modernidad. El carácter ideológico de la racionalidad moderna queda en evidencia al descalificar relatos de otras culturas, antiguas, o lejanas como propio de salvajes, perteneciente a una época pre-científico. Resulta significativo este

7 LEHMANN, Karl. El horizonte hermenéutico de la exégesis histórico crítica. In: SCHREIBER, Josef (Ed.). Introducción a los métodos de la exégesis bíblica. Barcelona: Herder, 1974.

8 ASSMANN, Hugo. El sujeto histórico de la teología de la liberación. In: PIXLEY, Jorge V.; BASTIAN, Jean Pierre. Praxis cristiana producción teológica. Salamanca: Sígueme, 1979. p. 42.

9 SOUSA SANTOS, Boaventura de. Una epistemología del Sur. México: Clacso Coediciones Siglo XXI, 2009. p. 31.

${ }^{10}$ DUCH, Lluís. Mito, interpretación y cultura. Barcelona: Herder, 2002. p. 225.

11 RATZINGER, Joseph. Interpretação Bíblica em crise: sobre a questão dos fundamentos e abordagem da exegese hoje. In: POTTERIE, Ignace de La; GUARDINI, R.; RATZINGER, J. Exegese cristã hoje. Petrópolis: Vozes, 1996. p. 111.

${ }^{12}$ LEVORATTI Armando. Hermenéutica y Teología. Buenos Aires: Lumen, 1997. p. 46. 
punto, pues en opinión de no pocos autores, la pretensión de los métodos histórico-crítico estaba definida paradójicamente por un rechazo del mito entendido como pre-científico a cambio de la objetividad científica:

la modernidad erigiéndose en contra del mito, construye sus propios mitos [...] La modernidad intenta definirse en contra del mito. El mito parece el pasado atávico de la humanidad, la razón moderna como la razón que sustituye los mitos. El mito parece ser lo primitivo, la razón ilumina y deja atrás el mito ${ }^{13}$.

El rechazo de los a priori ideológicos resulta injustificado al comprender que la interpretación de todo texto se realiza como participes de una cultura y más aún todo texto es considerado como tal, al interior de las creencias, cosmovisiones y valores compartidos de una cultura. En los manuales en uso conceptos fundamentales como ideología, cultura, imaginarios sociales no aparecen aplicados al concepto de texto salvo en pasajes aislados. Por el contrario, lo característico de la siguiente etapa será la relación entre discurso e ideología. Este contraste no es menor pues refleja la consciencia de estar en medio de diversas teorías semióticas particulares del texto. Por consiguiente la necesidad de re-formular categorías semióticas generales pareciera ser un imperativo.

Así las cosas, la reformulación semiótica del marxismo llevado a cabo por $\mathrm{L}$. Althusser implicaba establecer una doble vinculación entre ideología e inconsciente. Por un lado, expresa en 1966 en carta 1 a D. que: "una vez surgida la nueva estructura funciona en forma intemporal, exactamente como el inconsciente. [...] todo modo de producción es eterno"14. Por otro, Althusser explica la relación entre discurso e ideología/inconsciente a partir de la afirmación de Lacan "el inconsciente está estructurado como lenguaje", sosteniendo que el lenguaje implica dos estratos uno (fonológico y de los significantes) y otro estrato, el cual no está conformado por un "significado", sino que son "los mecanismos de combinación de los significantes. Son las leyes de estos mecanismos las que constituyen la estructura de la que se trata en la tesis, esa estructura por medio de la cual (y solo por medio de la cual,) el inconsciente se parece al lenguaje" ${ }^{\prime 15}$. En este contexto del surgimiento del inconsciente, Althusser argumenta a partir del funcionamiento intemporal del inconsciente "el inconsciente funciona como estructura intemporal"16 introduce una definición de ideología, que ya adelanta la que será formulada posteriormente:

lo ideológico no se reduce a los sistemas conceptuales de la ideología, sino que es una estructura imaginaria que existe no solo en la forma de conceptos sino también en forma de gestos, actitudes, conductas, intenciones, aspiraciones, rechazos, permisos, interdicciones, etc $^{17}$.

${ }^{13}$ HINKELAMMERT, Frank. Crítica de la razón mítica. Costa Rica: DEI, 2007. p. 41.

${ }_{14}$ ALTHUSSER, Louis. Escritos sobre psicoanálisis Freud y Lacán. México: XXI, 1996. p.81.

15 ALTHUSSER, 1996, p. 83.

${ }_{16}$ ALTHUSSER, 1996, p. 93

17 ALTHUSSER, 1996, p. 93. 
Esta estructura imaginaria multiforme es lo que vincula la ideología a la cultura y que volvemos a encontrar en Los aparatos ideológicos (1970): "La ideología [...] es en esa sobredeterminación de lo real por lo imaginario y de lo imaginario por lo real"18. El marxismo althusseriano propone así una semiótica de la cultura esbozando una teoría semiótica general del psicoanálisis ${ }^{19}$.

En una perspectiva distinta, del análisis del discurso, autores como T. van Dijk da la siguiente definición de ideología:

La base de las representaciones sociales compartidas por los miembros de un grupo. Esto significa que la ideología permite a los pueblos, como a los miembros de un grupo, organizar la serie de creencias sociales sobre lo que sea el caso, bueno o malo, correcto o equivocado para ellos y para actuar correspondientemente ${ }^{20}$.

Se trata de una definición semiótica de ideología en la cual, la ideología no es entendida como desviación o falsa conciencia de la realidad, sino como "representaciones sociales compartidas por los miembros de un pueblo", lo cual posee elementos comunes con la definición de Althusser; es importante atender que ambos establecen una vinculación de la ideología con creencias sociales, normas, diversas, actitudes, conductas, intenciones, aspiraciones, rechazos, permisos, interdicciones, etc.

En este contexto teórico, los estudios bíblicos del siglo XX se muestran ajenos y desfasados, más bien siguiendo el modelo de una exégesis positivista, en la cual la ideología es considerada como espurio a la fe religiosa. Lentamente la exégesis se ha abierto a nuevos paradigmas en los cuales el concepto de texto es discutido en relación al de cultura. Asi las cosas ¿tiene algún sentido hablar de la historia de las formas al margen, prescindiendo, de la cultura y la ideología en la cual está inserto todo género? ¿Acaso no se refleja una cierta abstracción ideológico estudiar géneros literarios como si fueran entidades universales absolutas? asi p.e. ¿tiene algún sentido comparar un pesher con un comentario bíblico? O comparar una profecía ex-eventu con algún genero del siglo XX?. Pareciera ser que no. ¿Dónde está la teoría semiótica que integra el texto como expresión de la memoria de un pueblo y el texto como fuente e instrumento de conocimiento del pasado? Si como lo señala Lotman cada texto se inscribe dentro de una memoria colectiva, un texto es un "condensador de memoria cultural" 21 y como condensador, la memoria es un trabajo del imaginario y por tanto es la selección, un recorte fragmentario de la identidad grupal ${ }^{22}$ ¿cómo conjugamos esta visión del texto lotmaniana con la del texto de los métodos histórico-críticos?

18 ALTHUSSER, Louis. Pour Marx. Paris: Editions La Découverte, 1986. p. 240ss.

19 ALTHUSSER, 1996, p. 105ss.

20 VAN DIJK, Teun. Ideology, Multidisciplinar approach. New Delhi; London: AGE Publications; Thousand Oaks, 1998. p. 8.

${ }^{21}$ LOTMAN, Yuri. M. Universe of the mind: a Semiotic Theory of Culture. Bloomington, Indianapolis: Indiana University Press, 1990. p. 18.

22 NOGUEIRA SOUZA, Paulo A. de. Linguagens da religião. Desafios, métodos e conceitos centrais. São Paulo: Paulinas, 2012. p. 18. 


\section{Objetivo y método}

El título "Exégesis, texto e imaginario", no pretende identificar exégesis e imaginario social sino comparar y analizar el carácter paradójico de la problemática. El ingreso de los métodos histórico critico está acompañado de la paradoja del rechazo del relato mítico constituyéndose a sí mismo en aquello que rechaza. Por contraste, el panorama de la exégesis del siglo XX está marcado por el pluralismo teórico-metodológico el cual arriesga una promiscuidad teórica y metodológica. Dicho pluralismo caracterizado por un regreso a una nueva valoración de nuevos sujetos, nuevas perspectivas y racionalidades conlleva el desafío de esbozar una teoría semiótica general de la Palabra de Dios y el desafío de reflexionar sobre el carácter epistemológico del cambio de paradigma ${ }^{23}$. El problema no es sencillamente situarse entre diversas teorías semióticas particulares o en confrontación de unas con otras, o de una perspectiva metodológica diacrónica en confrontación con otra sincrónica, sino lograr comprender que la nueva situación epistemológica en la que nos encontramos obliga a realizar una teoría de una semiótica general del trabajo exegético en el cual somos más conscientes que antes de la hipoteca ideológica que pesa sobre nosotros y por lo que no podemos trabajar exegéticamente desde fuera de nuestra propia cultura ya que nuestra cultura vivida condiciona quiérase o no, nuestra labor científica.

Así las cosas, el artículo pretende esbozar los desafíos actuales de una teoría semiótica general de la Palabra de Dios tomando como punto de partida las teorías regionales del texto como la que formula los métodos histórico crítico, lo cual conlleva el desafío de estudiar las diversas teorías regionales del texto. De acuerdo a lo dicho y en vista de nuestro objetivo emplearemos un concepto semiótico de ideología formulado por T. van Dijk y L. Althusser el cual establece una relación entre el concepto de ideología/inconsciente y el de discurso.

\section{Una nueva comprensión del texto}

Los manuales en uso responden de manera marginal a la cuestión de la búsqueda de una teoría semiótica general del texto en cual nos hayamos, o el uso de diversas teorías del texto de manera ingenua o promiscua, no dimensiona la problemática que implica para la praxis exegética. El abuso de teorías textuales regionales diversas muestra la inconsistencia del estudio bíblico, y que demuestra el problema

${ }^{23}$ ZABATIERO, Julio. Manual de Exegese. São Paulo: Hagnos, 2007; EGGER, William. Lecturas del Nuevo Testamento. Navarra: Verbo Divino, 1990; KRÜGER, René. Métodos exegéticos. Buenos Aires: Isedet, 2001; CROATTO, Severino. Hermenéutica Bíblica. Para una teoría de la lectura como producción de sentido. Buenos Aires: Aurora, 1984; MORA PAZ, César; GRILLI, Massimo; DILLMANN, Reiner. Lectura pragmalingüistica de la Biblia. Teoría y aplicación. Navarra: Verbo Divino, 1999; DIAS, Cássio Murilo. Metodologia de Exegese Bíblica. São Paulo: Paulinas, 2000. 
de la falta de una teoría general del texto ${ }^{24}$. Con todo, no faltan los estudios ${ }^{25}$ que son conscientes del nuevo escenario poli-textual y la pérdida de una necesaria monosemia del concepto. Aún más, a esta situación poli-textual, Lotman afirma que estamos en la emergencia de nuevos textos: "la actualidad de un problema, indicar un dominio en el que están naciendo nuevas ideas científicas" ${ }^{26}$ y también señala Grilli "la pragmática se mueve en el contexto de una teoría del texto más amplia" ${ }^{27}$. No se trata tan sólo de nuevas disciplinas que han desarrollado un nuevo concepto de texto sino también este nuevo escenario de una pluralidad textual integra la aparición de nuevos textos como los petroglifos, pictogramas, relatos míticos de los pueblos afro-americanos y pueblos pre-colombinos, o más recientemente los testimonios de abusados por sacerdotes católicos, etc.

\section{El texto clásico}

Durante el siglo XX una vez que se comienza a constatar las incoherencias entre el texto bíblico y la investigación científica, se asiste a la emergencia de una nueva visión de lo que es considerado un texto. Los estudios de lingüística de F. Saussure Y el nacimiento del psicoanálisis freudiano y el estructuralismo de Levi-Strauss crean una nueva conciencia de la existencia de la comprensión sustancialista del texto clásico dentro de lo de que se ha llamado la ideología realista. Una caracterización del texto clásico está dada por Garcia-Jalón quien clasifica dichos textos diferenciados como tales a partir del criterio de verdad: texto original-verdadero, textos incoherentes y ficcionales, y textos equívocos ${ }^{28}$. El texto verdadero es aquel que comporta una relación con la realidad factual, y que representa un acontecimiento que existe en el mundo real. La primera característica del concepto clásico de texto se origina en la metafísica griega. La distinción sustancia/forma surge constituye a un texto como texto compuesto de una sustancia y de una forma particular. El texto clásico tiene un sentido único y esto, paradójicamente en un doble sentido. De un lado, se presume que el texto contiene un sentido y es uno solo, de otro lado que el sentido procede unilateralmente del autor y va hacia el lector: según la concepción clásica contiene una sola verdad. El texto clásico es una entidad cerrada, clausurada y el sentido radica está depositado en la misma materialidad del texto, es decir es un texto sin cultura, a-histórico. La existencia de textos incoherentes y ficcionales son re-situados por medio de la retórica clásica en el ámbito de los tropos y de los cuatro sentidos de la Escritura.

24 VATER, Heinz. Einführung in die Textlinguistik. Munich: UTB; William Fink, 1992. p. 20.

${ }^{25}$ BERTOCCELLI, Marcella. Qué es la pragmática. Barcelona: Paidós, 1993; MORA PAZ; GRILLI; DILLMANN, 1999.

${ }^{26}$ LOTMAN, Iuri. La semiósfera I. Semiótica de la cultura y del texto. Madrid: Frónesis cátedra universitat de Valéncia, 1996. p. 63.

27 MORA PAZ, 1999, p. 65.

28 GARCÍA-JALON, Santiago. Linguística y exegeses bíblica. Madrid: Biblioteca de autores cristianos, 2011. p. 70ss. 
En este nuevo escenario la lingüística aportó a una teoría del concepto semiótico del texto una ampliación al referir el texto al concepto de sistema estructurado de lengua y habla. El cambio de paradigma aportado por la lingüística impulsado por F. Saussure (1857-1913) ha significado un giro copernicano. A pesar de que este autor no redactó ningún libro en vida, su curso de lingüística general tuvo un impacto de largo alcance. En su curso general sostiene que la lingüística "es una ciencia que estudia la vida de los signos en el seno de la vida social" 29 esto significa un teoría semiótica regional del texto que ciertamente significa un cambio radican en la comprensión del lenguaje humano ya no considerado al lenguaje como el reflejo de una esencia metafísica sino a partir de su estructura social inmanente. El estructuralismo francés, rápidamente sacó consecuencias revolucionarias de la aplicación de este modelo lingüístico del texto para el análisis sociocultural que se aplicará a diversos fenómenos sociales. Klaus Brinker describe la existencia de dos conceptos semióticos de texto en la lingüística, la primera procedente de la lingüística estructural según la cual el texto sería "una coherente sucesión de frases"30. Los aportes semióticos son bien conocidos. El texto consiste en una "estructura" en que la coherencia será vista específicamente desde el punto de vista del léxico-gramatical. En la segunda perspectiva, llamada comunicacional, el texto es comprendido pragmáticamente, es decir el texto no como una serie de frases entendida gramaticalmente, sino como estructura socio-cultural formada por una "compleja acción comunicativa" 31 . Uno de los fundamentales aportes de la lingüística radica en cambiar el paradigma instrumental del lenguaje oral o escrito al subrayar que el lenguaje no es un instrumento o fuente de conocimiento como se aprecia en los métodos histórico críticos sino un problema en el sentido que es un estructura/sistema abierto en el cual el sujeto no se sitúa al margen del lenguaje sino por el contrario, el mismo está inserto en el sistema de la lengua. Producto de este desarrolla, surgirá la teoría del texto que nace como una sub-disciplina de la lingüística del texto ${ }^{32}$ integrando a la retórica, poética, sicología, etc.

\section{Ampliación psicoanalítica del concepto de texto}

Hay que decir que Freud no posee una teoría semiótica general del sueño como texto onírico, sino más bien se aproxima desde una perspectiva fisiológica-hermenéutica y de manera esporádica a una teoría regional del relato onírico. No obstante, L. Althusser demuestra el interés de Freud y Lacan por una teoría semiótica general del

29 SAUSSURE, Ferdinand. Curso de Lingüistica General. Buenos Aires: Losada S.A., 1945. p. 42.

${ }^{30}$ BRINKER, Klaus. Linguistische Textanalyse. Eine Einführung in Grundbegriffe und Methoden. Berlin: Erich Schmidt Verlag, 1985. p. 14.

${ }^{31}$ BRINKER, 1985, p. 15; BEAUGRANDE, Robert-Alain; DRESSLER, Wolfang U. Introducción a la lingüística del texto. Barcelona: Ariel Lingüística, 1997. p. 35.

32 VATER, 1992, p. 14-15. 
sicoanálisis ${ }^{33}$. No obstante, es innegable que en su reflexión sobre el sueño y el inconsciente muestra elementos importantes para una teoría regional del texto. Ciertamente, la discusión sobre el estatuto semiótico de texto aplicado a los sueños emerge desde los primeros escritos y posteriormente en los estudios de Lacan, con una pretensión más amplia de todos los productos de la cultura. De manera sintética podemos señalar:

a. Un texto está constituido como tal dentro de la secuencia de otros textos de una cultura. Una primera característica semiótica del texto radica en que Freud comprende el relato del sueño dentro del sistema de asociaciones semióticas socio-cultural.

b. Carácter fragmentario del texto. En diversas oportunidades Freud caracteriza las imágenes manifiestas del inconsciente como fragmentos ${ }^{34}$. Esta fragmentación significa que las imágenes manifiestas del sueño son una especie de "caleidoscopio" en el cual no se producen las operaciones lógicas del alma sino por el contrario el texto inconsciente es incoherente y contradictorio.

c. Censura como característica semiótica entre experiencia y lenguaje. Una tercera característica semiótica del sueño radica en la censura entre contenido manifiesto expresado mediante imágenes e ideas latentes "se nos muestran como dos versiones del mismo contenido, en dos idiomas distintos" ${ }^{\prime 35}$. El texto queda estructurado como un texto quebrado, de tal manera que se requiere una traducción realizada entre dos idiomas distintos. Freud inscribe la censura como un fenómeno lingüístico:

el contenido manifiesto no es dado como un jeroglifo, para cuya solución habremos de traducir cada uno de los signos al lenguaje de ideas latentes [...] esforzándose en sustituir cada imagen por una silaba o una palabra susceptible de ser reemplazada por ella ${ }^{36}$.

Es importante notar el carácter escindido de la escritura entre no-texto y texto que menciona Freud y que asumirá Lotman, en ambos se trata de un fenómeno de traducción de un lenguaje a otro. Las imágenes devienen una primera semiófera intra-psíquica la cual luego es traducida por el paciente a la propia cultura semiótica.

Ampliación social del concepto de texto

Apreciamos una nueva emergencia de una teoría regional del concepto de texto social dentro de diversas corrientes filosóficas ${ }^{37}$. Dicha ampliación consiste que al igual que otras corrientes de pensamiento, la lingüística, el estructuralismo, y el marxismo que comprenden la sociedad y la praxis como el referente de todo texto. Levi-Strauss menciona el carácter sistémico del lenguaje mítico en quien establece

${ }^{33}$ ALTHUSSER, 1996, p. 109ss.

${ }^{34}$ FREUD, Sigmund. Obras completas. Tomos I-II. Madrid: Biblioteca Nueva, 1973. p. 678.

${ }^{35}$ FREUD, 1973, p. 516.

${ }^{36}$ FREUD, 1973, p. 516.

${ }^{37}$ AIRTON, José da Silva. Leitura sócio-antropológica. In: DIAS, 2000, p. 417. 
la semejanza entre lingüística y sociología: “[...] Como los fonemas, los términos de parentesco son elementos de significación; como ellos, adquieren esta significación sólo a condición de integrarse en sistemas" ${ }^{\text {"38 }}$. A mediados del siglo XX este paso entre lingüística y sociología es considerado revolucionario y explica la importancia que le dan los autores a fenómenos sociales como el deporte, la moda, y el arte entre otros y no sólo referido a obras literarias. La sociedad funciona como un sistema de textos, en los cuales la significación se logra en la relación codificada que establecen unos elementos con otros. De esta manera, el texto no termina en sí mismo, ni remite a una contenido esencial, éste está definido por un objeto que está fuera de él mismo. Ricoeur señala en esta misma línea que "la noción de texto es un buen paradigma para la acción humana y por otra que la acción humana es un buen referente para toda categoría de textos" 39 . Y también H. Lefebvre sostendrá en este mismo tenor que "la praxis se encara como un texto como un mensaje más vasto y confuso, que comprende diversos campos ${ }^{40} \mathrm{e}$ invita al lector a mirar a su alrededor: "la calle con las casas, la gente con su rostro, sus gestos, sus vestimentas; los departamentos con sus muebles. Tenemos ante los ojos un texto social"41 y también: "un texto social es un campo sensible cargado de sentido gracias a los signos y valores" ${ }^{\prime 2}$. A diferencia del análisis estructural que contiene dos dimensiones sintagmática y paradigmática, Lefebvre añade a la dimensión sintagmática y paradigmática, otra dimensión simbólica. De esta manera la inteligibilidad del texto se consigue a través del desciframiento de su código, esto es, comprender el código de la praxis..."por tanto debe llegarse a la praxis a través del lenguaje, considerándolo un código, formalizándolo hasta elaborarlo como un código" ${ }^{43}$, pues la praxis se comprende como un texto, como un mensaje vasto y confuso, que comprende diversos campos y donde el lenguaje corriente es su código ${ }^{44}$.

Podemos apreciar que diversas aproximaciones del método de interpretación bíblica tienen en estas reflexiones sus antecedentes más cercanos. La teoría semiótica de los signos de los tiempos y del texto social propuesto por algunos teólogos de la liberación en cuanto que la praxis y la historia son el texto primero en el cual los cristianos deben discernir la voluntad de Dios tiene aquí su fundamento teórico. Y el desconocimiento de estos antecedentes resulta sorprendente en la trasnochada exégesis del siglo XX. En Latinoamérica, esta coherencia entre texto-en-si y praxis como texto se aprecia recién en autores como G. Gutiérrez, C. Mesters y J. S. Croatto. Este último señala que "Texto y acontecimiento, o texto y praxis, se condicionan mutuamente desde el origen y desde el punto de vista hermenéutico"45. El paso de una exégesis de los textos-en-sí al texto-para-nosotros es uno de los aspectos centrales de la herme-

\footnotetext{
${ }^{38}$ LEVI-STRAUSS, Claude. Antropología estructural. Buenos Aires: Editorial universitaria, 1968. p. 32.

39 RICOEUR, Paul. Hermenéutica y acción: De la hermenéutica del texto a la hermenéutica de la acción. Buenos Aires: Docencia, 1985. p. 87.

${ }^{40}$ LEFEBVRE, Henri. Lenguaje y sociedad. Buenos Aires: Proteo, 1967. p. 222.

${ }^{41}$ LEFEBVRE, 1967, p. 217.

42 LEFEBVRE, 1967, p 217.

${ }^{43}$ LEFEBVRE, 1967, p. 181.

44 LEFEBVRE, 1967, p. 181.

${ }^{45}$ CROATTO, 2002, p. 10.
} 
néutica de la liberación, pero la cuestión no debe ser considerado como un oportunismo metodológico sino en una nueva teoría general del concepto del texto que aflora y que está constituida por las voces silenciadas y la experiencia marginal como texto: "punto de partida de un texto es alguna forma de experiencia: una práctica, un suceso significativo, una cosmovisión, un estado de opresión, un proceso de liberación, una vivencia de gracia y salvación, etc". ${ }^{46}$ Cuestión no reconocida siempre por teólogos latinoamericanos. En este mismo contexto resulta fundamental aceptar que los pueblos Latinoamericanos tienen sus propios textos silenciados por la misma exégesis, son los textos de los sin voz, de los que sufren de manera callada: son los textos de los pictogramas, de los mitos y relatos de los pueblos originarios, de víctimas de abuso ${ }^{47}$. Estos nuevos textos son el testimonio de víctimas, textos no normativos, ni oficiales, y representan una emergencia de un nuevo tipo de textos en Latinoamérica. Los textos normativos como la Escritura, los dogmas, Constituciones, Derecho canónico, reglas, etc. representan una hegemonía epistémica, un límite cognitivo-político para discriminar a los protagonistas sociales y políticos de una religión o nación.

\section{Ampliación semiótica del concepto de texto}

Encontramos una ampliación semiótica regional del texto en autores como R. Barthes y Y. Lotman, el primero utiliza un concepto de texto contrapuesto al de obra. Para este autor texto y obra no son lo mismo: "el texto es [...] fundamentalmente distinto de la obra literaria" ${ }^{48}$, el texto es descrito en términos dialecticos en oposición a conceptos estructuralistas el texto es "una práctica significativa no es una estructura sino una estructuración; no es un objeto, sino un trabajo y un juego; no es un grupo de signos cerrados, investidos con un significado para ser redescubiertos sino es un volumen de indicios en desplazamiento"49. Tenemos aquí tres conceptos, el texto como una práctica; el texto como estructuración; el texto como texto abierto.

a) El texto no se experimenta más que en un trabajo, en una producción. El texto está ligado a un pasar, una travesía que el lector realiza en el proceso de producción, de trabajo. Por consiguiente un primer aspecto importante que desataca Barthes es que un texto no se constituye como un objeto-en-sí, sino por una relación de trabajo que se establece entre el lector y la obra.

b) Esto nos coloca en la línea de que el texto es una actividad del lector que lo lleva a los márgenes, a los límites de las reglas o de la realidad. A esto se debe que Barthes señale que la experiencia textual es siempre paradójica, pues no hace salir,

${ }^{46}$ CROATTO, 2002, p. 59.

${ }^{47}$ Tomado de: $<$ https://www.cooperativa.cl/noticias/pais/iglesia-catolica/jaime-concha-denunciante-del-caso-maristas-nuestras-vidas-han-sido/2018-04-16/080752.html>.

${ }^{48}$ BARTHES, Roland. Semiotic Challenge. Berkeley: University of California Press, 1988. p. 7.

49 BARTHES, 1988, p. 7. 
trascender los márgenes: "el texto es lo que llega hasta los límites de las reglas de la enunciación (la racionalidad, la legibilidad, etc.) [...] el texto es siempre paradójico" $" 50$.

c) Barthes contrapone el carácter cerrado y mudo de la obra en cambio el texto está siempre descentrado y radicalmente sin cierre ${ }^{51}$. El descentramiento del texto se aprecia en el concepto de intertextualidad. Barthes nos propone entender el texto como entretexto. La intertextualidad significa entender que todo texto es un inter-texto que viene desde y va hacia otro lugar, el texto "es un tejido de citas provenientes de los mil focos de la cultura" 52 .

Esta nueva comprensión del texto como inserto en la cultura nos recuerda la teoría regional del sueño psicoanalítico el cual está inserto en una secuencia de conexiones culturales y nos hace comprender que el aislamiento de un texto es negar toda comprensión de su sentido. En el caso de la semiótica de texto de Y. Lotman el punto de partida es la distinción entre espacio semiótico y aislado, discontinuo a "textos extra-semióticos o no-textos" 53 . El concepto de texto, el cual es polisémico, se comprende por tanto dentro de un espacio semiótico y un no-texto corresponde a un extra-semiótico espacio. ¿Qué está entendiendo Lotman por "no-texto"? el concepto de no-texto, el cual se repite en diversos escritos, muestra que el concepto de texto lotmaniano depende del espacio semiótico del observador. Así, un texto perteneciente a un espacio semiótico puede ser considerado como un no-texto, una periferia semiótica, por un observador extra-semiótico ${ }^{54}$.

Las actuales teorías de los imaginarios sociales y de la construcción social del silencio, sostienen que desde un punto de vista semiótico, a) todo texto es parte de un silenciamiento social; b) el núcleo de cada texto está constituido por una fractura o silencio como el esqueleto sobre el cual se construye su código y textualidad ${ }^{55}$. Resulta interesante comprender el carácter liberador que posee esta perspectiva, pues en nuestro contexto de exclusión y silenciamiento expresa que hay textos no reconocidos como tales, son los textos apócrifos, textos marginales del imperio, textos de los sin voz de ayer y hoy, los cuales representan textos emergentes no aceptados como tales por la cultura hegemónica eclesial o social. La oposición texto escrito-oral muestra no-textos como textos de los márgenes de una cultura que consagra como tales un específico modelo cultural pero que considera sin valor epistemológico los textos de culturas ágrafas, de mitos indígenas, de las víctimas de abusos, etc. ${ }^{56}$

\footnotetext{
${ }^{50}$ BARTHES, Roland. De la obra al texto. In: BARTHES, Roland. El susurro del lenguaje. Barcelona: Paidos Ibérica, 1994. p. 76.

${ }^{51}$ BARTHES, 1994, p. 76.

52 BARTHES, 1994, p. 69.

${ }^{53}$ LOTMAN, Yuri. On the semiosphere. Sign Systems Studies, v. 33, n. 1, p. 205- 229, 2005. p. 205.

54 LOTMAN, 1996, p. 213.

55 CARBULLANCA, Cesar. “[...] El mundo retornará a su primer silencio.” Estudio sobre el silencio y el lenguaje en relatos apocalípticos judeo-cristianos. HORIZONTE - Revista de Estudos de Teologia e Ciências da Religião, v. 16, n. 51, p. 1.042-1.065, 31 dez. 2018.

${ }^{56}$ LOTMAN, 1978, p. 235.
} 


\section{Consideraciones finales}

Las reflexiones que hemos presentado representan solo un esbozo de una teoría semiótica del texto, fundamental para el trabajo exegético, desarrollando dos aspectos fundamentales para una semiótica de la Palabra de Dios. Hemos subrayado el carácter ideológico que posee la exégesis que radica, en una inconciencia o ausencia, de una teoría semiótica general del texto lo cual está evidenciado en una equivocada formulación de la ideología y del concepto de texto (tanto del texto canónico o apócrifo de la antigüedad como el de hoy), así como del lugar que ocupan los métodos exegéticos dentro de esta problemática. Hay cuestiones complejas ciertamente, en la elaboración de una teoría general dada la ampliación del concepto de texto en que nos encontramos, pero se comprende mal aquella situación si se le considera meramente desde una perspectiva instrumental. La radicalidad del planteamiento se aprecia más claro si consideramos que la tan nombrada relación exégesis-hermenéutica es colocada en tensión, pues precisamente la pregunta por el texto no se sitúa en el nivel metodológico optativo sino en el de una teoría semiótica del texto general que integre las diversas teorías regionales, de lo contrario cabría preguntar si ¿es coherente trabajar con dos e incluso tres teorías del texto en un mismo desarrollo del trabajo exegético? Pareciera poco convincente desde un punto de vista científico el empleo aleatorio de una teoría del texto para los métodos diacrónicos y otro distinto para los métodos sincrónicos. Acaso ¿no resulta un tanto ingenua la llamada a realizar una buena exégesis para una buena hermenéutica? Al estudiar cualquier texto del pasado, entiéndase Heródoto, textos apócrifos o canónicos, o de un texto actual, están implicada la cuestión fundamental de una teoría semiótica del texto coherente entre el texto analizado y el biblista inserto en una textualidad cultural. Por otro lado esta ampliación nos ayuda a comprender las diversas teorías regionales del texto marcadas por el carácter textual de la cultura, la fragmentariedad e incoherencia del texto; la fractura y silencio que conlleva en el texto.

\section{Referências}

AIRTON, José da Silva. Leitura sócio-antropológica. In: DIAS, Cássio Murilo. Metodologia de Exegese Bíblica. São Paulo: Paulinas, 2000. p. 355-411.

ALTHUSSER, Louis. Escritos sobre psicoanálisis Freud y Lacán. México: XXI, 1996.

ALTHUSSER, Louis. Pour Marx. Paris: Editions La Découverte, 1986.

ASSMANN, Hugo. El sujeto histórico de la teología de la liberación. In: PIXLEY, Jorge V.; BASTIAN, Jean Pierre. Praxis cristiana producción teológica. Salamanca: Sígueme, 1979.

ASSMANN, Hugo. Teología desde la praxis de la liberación. Ensayo teológico desde la América dependiente. Salamanca: Sígueme, 1973.

ASSMANN, Jarl. Monotheism and Polytheism. In: JOHNSTON, Sarah Iles (Org.). Religions of the Ancient World. A Guide. Cambridge: Cambridge Mass., 2004. p. 17-31. BARTHES, Roland. De la obra al texto. In: BARTHES, Roland. El susurro del lenguaje. Barcelona: Paidos Iberica, 1994. p. 65-80.

BARTHES, Roland. Semiotic Challenge. Berkeley: University of California Press, 1988.

BEAUGRANDE, Robert-Alain; DRESSLER, Wolfang U. Introducción a la lingüística del texto. Barcelona: Ariel Lingüística, 1997. 
BERTOCCELLI, Marcela. Qué es la pragmática. Barcelona: Paidós, 1993.

BRINKER, Klaus. Linguistische textanalyse. Eine Einführung in Grundbegriffe und Methoden. Berlín: Erich Schmidt Verlag, 1985.

CARBULLANCA, Cesar. “...El mundo retornará a su primer silencio.” Estudio sobre el silencio y el lenguaje en relatos apocalípticos judeo-cristianos. HORIZONTE - Revista de Estudos de Teologia e Ciências da Religião, v. 16, n. 51, p. 1.042-1.065, 31 dez. 2018.

CROATTO, Severino. Hermenéutica Bíblica. Para una teoría de la lectura como producción de sentido. Buenos Aires: Aurora, 1984.

DIAS, Cássio Murilo. Metodologia de Exegese Bíblica. São Paulo: Paulinas, 2000.

DUCH, Lluís. Mito, interpretación y cultura. Barcelona: Herder, 2002.

EGGER, William. Lecturas del Nuevo Testamento, Navarra: Verbo Divino, 1990.

FREUD, Sigmund. Obras completas. Tomos I-II. Madrid: Biblioteca Nueva. 1973.

GARCÍA-JALON, Santiago. Linguística y exegeses bíblica. Madrid: Biblioteca de autores cristianos, 2011.

HINKELAMMERT, Frank. Crítica de la razón mítica. Costa Rica: DEI, 2007.

HOLEMN, Tom; PORTER, Stanley (Ed.). Handbook for the Study of the Historical Jesus. Leiden; Boston: Brill, 2001.

KRÜGER, René. Métodos exegéticos. Buenos Aires: Isedet, 2001.

LEFEBVRE, Henri. Lenguaje y sociedad. Buenos Aires: Proteo, 1967.

LEFEBVRE, Henri. Contra los tecnócratas. Buenos Aires: Granica S.A., 1972.

LEHMANN, Karl. El horizonte hermenéutico de la exégesis histórico crítica. In: SCHREIBER, Josef(Ed.). Introducción a los métodos de la exégesis bíblica. Barcelona: Herder, 1974. p. 61-108. LEVI-STRAUSS, Claude. Antropología estructural. Buenos Aires: Editorial universitaria, 1968. LEVORATTI, Armando. Hermenéutica y Teología. Buenos Aires: Lumen, 1997.

LOTMAN, Yuri. La semiósfera I. Semiótica de la cultura y del texto. Madrid: Frónesis cátedra universitat de Valéncia, 1996.

LOTMAN, Yuri M. Universe of the mind: a Semiotic Theory of Culture. Bloomington, Indianapolis: Indiana University Press, 1990.

LOTMAN, Yuri. On the semiosphere. Sign Systems Studies, v. 33, n. 1, p. 205- 229, 2005.

MORA PAZ, César; GRILLI, Massimo; DILLMANN, Reiner. Lectura pragmalingüística de la Biblia. Teoría y aplicación. Navarra: Verbo Divino, 1999.

NOGUEIRA, Paulo. El cristianismo primitivo como religión popular. Salamanca: Sígueme, 2019. RATZINGER, Joseph. Interpretação Bíblica em crise: sobre a questão dos fundamentos e abordagem da exegese hoje. In: POTTERIE, Ignace de La; GUARDINI, R.; RATZINGER, J. Exegese cristã hoje. Petrópolis: Vozes, 1996. p. 100-115.

RICOER, Paul. Hermenéutica y acción: De la hermenéutica del texto a la hermenéutica de la acción. Buenos Aires: Docencia, 1985.

SAUSSURE, Ferdinand. Curso de Lingüistica General. Buenos Aires: Losada, S.A., 1945. SOUSA SANTOS, Boaventura de. Una epistemología del Sur. México: Clacso Coediciones Siglo XXI, 2009.

SOUZA NOGUEIRA, Paulo A. de. Linguagens da religião. Desafios, métodos e conceitos centrais. São Paulo: Paulinas, 2012.

VAN DIJK, Teun. Ideology, Multidisciplinar approach. New Delhi; London: AGE Publications; Thousand Oaks, 1998.

VATER, Heinz. Einfürung in die Textlinguistik. Munich: UTB; William Fink, 1992.

ZABATIERO, Julio. Manual de Exegese. São Paulo: Hagnos, 2007. 